\title{
DINÂMICA E CONCENTRAÇÃO DA PRODUÇÃO DE FEIJÃO NA REGIÃO CENTRO-OESTE DO BRASIL, 1990 A 2013
}

\author{
DYNAMICS AND CONCENTRATION OF BEAN PRODUCTION IN \\ MIDWEST REGION OF BRAZIL, 1990 TO 2013
}

\author{
Alcido Elenor Wander ${ }^{1}$ \\ Paulo Eterno Venâncio Assunção ${ }^{2}$
}

\begin{abstract}
RESUMO
O objetivo deste estudo foi caracterizar os padrões de concentração da produção de feijão e o modelo de migração que houve em relação à produção de feijão nos municípios que compõem os estados da região Centro-Oeste do Brasil no período de 1990 a 2013. Foram identificados os municípios maiores produtores e ordenados em ordem decrescente por quantidade produzida, classificando-os em quatro quartéis (intervalos entre dois quartis). Foi possível confirmar uma tendência de concentração da produção de feijão da região Centro-Oeste em alguns poucos municípios (Cristalina e Luziânia, Goiás; Sorriso e Primavera do Leste, Mato Grosso).
\end{abstract}

Palavras-chave: Feijão em Goiás. Feijão em Mato Grosso. Feijão em Mato Grosso do Sul.

\begin{abstract}
The objective of this study was to characterize the patterns of concentration and migration of bean production in the municipalities within the states of the Midwest region of Brazil from 1990 to 2013. The main bean producing municipalities were identified and sorted in descending order by production, classifying them into four quartiles. It was possible to confirm a trend towards concentration of bean production in the Midwest region in a few municipalities (Cristalina and Luziânia, Goiás state; Sorriso and Primavera do Leste, Mato Grosso state).
\end{abstract}

Keywords: Beans in Goiás state. Beans in Mato Grosso state. Beans in Mato Grosso do Sul state.

\section{Introdução}

A região Centro-Oeste é marcada pela forte presença do agronegócio, e sua economia é voltada para a produção agrícola, seja de grãos, seja de fibras e carnes. O agronegócio brasileiro possui vantagens comparativas na produção de alguns produtos importantes, o feijão está entre eles. O feijão sempre foi um produto importante na alimentação dos brasileiros, faz parte da pauta de importações do país e poderá ser exportado em maiores quantidades nos próximos anos, caso a produção nacional de

\footnotetext{
${ }^{1}$ Faculdades Alves Faria (ALFA). Graduação em Agronomia pela Universidade de Kassel (1996), mestrado em Ciências Agrárias dos Trópicos e Subtrópicos (1998) e doutorado em Ciências Agrárias (2002), ambos na Georg August Universität Göttingene. Professor titular das Faculdades Alfa. Av. Perimetral Norte, 4129, Vila Joao Vaz, Goiânia, GO, CEP: 74445-190. E-mail: alcido.wander@alfa.br

${ }^{2}$ Universidade Federal de Goiás (UFG). Mestre em Agronegócio pela UFG. Avenida Esperança, s/n, setor Itatiaia, Goiânia, GO, CEP: 74690-900. E-mail: paulo_eterno05@hotmail.com
} 
tipos de grãos exportáveis seja ampliada, ou seja, o Brasil é um país importante no cenário mundial do feijão como produtor e importador (WANDER et al., 2007).

A produção de feijão no Brasil é caracterizada pela divisão em três safras: primeira safra, ou safra das águas; segunda safra, ou safrinha, que ocorre no fim das chuvas e a terceira safra, ou safra de verão, que ocorre com auxílio de pivô central. Esse calendário agrícola pode ser resumido da seguinte forma: a primeira safra é cultivada principalmente nas regiões Sul e Sudeste e na região de Irecê, na Bahia, cuja colheita está concentrada nos meses de dezembro a março. A colheita da segunda safra ocorre entre os meses de abril e julho, e a terceira, em que predomina o cultivo de feijão irrigado, está concentrada nos estados de Minas Gerais, São Paulo, Goiás/Distrito Federal e oeste da Bahia, e é ofertada no mercado entre julho e outubro. Embora esses períodos possam apresentar variações de ano para ano, é possível identificar que há colheita praticamente o ano todo, e que existe sobreposição de épocas em algumas regiões (FERREIRA et al., 2002).

O Centro-Oeste vem apresentando crescimento em sua produção anual de feijão, a região vem ganhando cada vez mais espaço no cenário nacional, e os estados que a compõem têm tido ganhos significativos em áreas plantadas e quantidades produzidas. Em 2013 o Centro-Oeste foi responsável pela produção de $22 \%$ do total de feijão produzido em todo o país, com uma produção de 626.239 toneladas de feijão (IBGE, 2014).

As atividades econômicas não se desenvolvem de forma uniforme no espaço, resultando em diferentes padrões de localização dessas atividades e, no caso do agronegócio, esse efeito não é diferente (WANDER, 2011). Na produção agrícola, seja a produção de carne, leite, frutos, grãos ou fibras, há uma tendência de concentração dessa produção em dada região (estado, microrregião ou município), ficando por muitas vezes apenas uma região responsável pela produção de todo o produto que está sendo explorado. Esse efeito recebe o nome de concentração da produção e está sujeito a acontecer com qualquer item de exploração agropecuária, pois dada região pode apresentar melhores condições de produção, de comercialização, de escoamento da produção e/ou tradição na produção do item.

Tendo em vista esse aspecto, entende-se que é fundamental conhecer melhor como a produção do agronegócio regional está concentrada ou não em determinadas 
regiões, assim o objetivo do trabalho foi caracterizar os padrões de concentração da produção de feijão e o modelo de migração que houve em relação à produção de feijão nos municípios que compõem os estados da região Centro-Oeste do Brasil no período de 1990 a 2013.

\section{Metodologia}

Foram utilizados os dados de quantidade produzida de feijão, por município, de todos os municípios da região Centro-Oeste do Brasil, considerando os anos 1990, 1995, 2000, 2005, 2010 e 2013. Esses dados foram obtidos da base de dados SIDRA do IBGE (IBGE, 2014), que caracteriza a produção agropecuária por municípios, permitindo sua utilização livre.

Dos municípios produtores, foram identificados os municípios que apresentam a maior produção de feijão na região Centro-Oeste nos anos de 1990, 1995, 2000, 2005, 2010 e 2013, para que se possa identificar o município que mais contribuiu para a produção desse grão da região, tornando possível identificar o primeiro município em produção, o segundo, o terceiro e assim por diante.

A metodologia utilizada para que houvesse a distinção entre os municípios produtores, foi o método dos quartéis: ${ }^{3}$ o quartel superior (Q4) é formado pelo menor conjunto de municípios produtores que respeitam o ordenamento e são suficientes para alcançar pelo menos $25 \%$ da produção efetiva da região Centro-Oeste; o terceiro quartel (Q3) é formado pelos municípios seguintes, até que consiga alcançar, em conjunto com o Q4, 50\% da produção efetiva da região; os outros municípios seguem a mesma lógica, com Q4 e Q3 em grupo até formar 75\% da produção efetiva, perfazendo o Q2, e os municípios restantes formando o quartel inferior que é o Q1 (WANDER, 2011). Não foram considerados quartis, porque se referem apenas aos pontos $25 \%, 50 \%, 75 \%$ e $100 \%$, enquanto os quartéis compreendem os intervalos entre os quartis e, portanto, são mais indicados para o estudo em questão.

Cabe ressaltar que como são municípios e que pode haver oscilações quanto à produção e a participação e até mudanças dos municípios que mais produziam, não é possível garantir que um quartel terá exatamente $25 \%$ da produção, inclusive, pode até acontecer que Q4 reúna 34,56\% da produção, ou que Q3 reúna 62,90\% da produção

${ }^{3}$ Conforme o Dicionário Eletrônico Aurélio versão 5.0 (2005): “6.Estat. Numa distribuição de frequência, conjunto de valores compreendidos entre dois quartis consecutivos". 
efetiva. A técnica utilizada apenas garante que se tenha o mínimo de municípios possíveis para determinar a porcentagem $(25 \%, 50 \%$ e $75 \%)$, incluindo o município que se sobressaiu e os outros abaixo dele, para que se forme o quartel e a análise possa ser utilizada (WANDER, 2011). O Distrito Federal não foi considerado como Unidade da Federação nesta pesquisa, pois constar apenas um município em representação, assim, preferiu-se desconsiderar sua participação e apenas caracterizada.

\section{Resultados e discussão}

A região Centro-Oeste apresenta uma produção de feijão importante para o cenário nacional. A região foi responsável por $9 \%$ da produção nacional de feijão em 1990, $6 \%$ em 1995, $9 \%$ em 2000, $13 \%$ em 2005, $16 \%$ em 2010 e $22 \%$ em 2013. Isso demonstra que o Centro-Oeste aumentou sua participação na produção nacional de feijão a partir de 1995. O Distrito Federal, mesmo sendo composto por apenas um município, apresenta uma grande produção de feijão. Em 1990, o DF produziu 7.506 toneladas, contribuindo com 4\% da produção de feijão do Centro-Oeste. Em 2000, o DF produziu 32.039 toneladas de feijão, contribuindo com $12 \%$ da produção do CentroOeste. Em 2010 sua produção foi de 49.007 toneladas, perfazendo 10\% de participação na produção total da região. Em 2013, foi de 25.032 toneladas, o que representou $4 \%$ da produção do Centro-Oeste. Percebe-se, assim, que o DF responde por uma produção expressiva para apenas um município.

\subsection{Concentração da produção em Goiás}

A característica da produção de feijão em Goiás é que ela é feita em três etapas, definidas como três safras, o que é possível em virtude do advento da irrigação, que possibilita uma maior margem de tempo para a exploração das safras de feijão. Na Tabela 1 são apresentadas as principais microrregiões produtoras de feijão no estado de Goiás em 2013. Os valores da produção são dados por toneladas. O que pode ser observado é que o entorno de Brasília lidera com a maior parte da produção goiana de feijão. Isso ocorre porque a região dispõe de uma expressiva área irrigada, permitindo o cultivo ao longo do ano. Nessa região predominam lavouras maiores e mais tecnificadas. 
Tabela 1 - Produção de feijão (toneladas) por microrregiões do estado de Goiás, 2013

\begin{tabular}{lc}
\hline Microrregião & Produção (t) \\
\hline Entorno de Brasília & 144.607 \\
Sudoeste de Goiás & 56.420 \\
Catalão & 18.067 \\
Rio Vermelho & 16.001 \\
Pires do Rio & 11.933 \\
Chapada dos Veadeiros & 10.027 \\
Meia Ponte & 8.867 \\
Porangatu & 8.202 \\
Anápolis & 5.005 \\
Vale do Rio dos Bois & 4.407 \\
Aragarças & 3.936 \\
Vão do Paranã & 3.925 \\
Ceres & 1.423 \\
\hline Totânia & 902 \\
& 305 \\
\hline
\end{tabular}

Fonte: elaborada pelos autores a partir de dados do IBGE (2014).

A Tabela 2 apresenta a participação do estado de Goiás na produção de feijão do Centro-Oeste e do Brasil nos anos 1990, 1995, 2000, 2005, 2010 e 2013. O que fica evidente é que o estado tem ganhado importância na produção de feijão tanto no CentroOeste, como no cenário nacional. No Centro-Oeste, desponta nos últimos anos como um dos principais produtores de feijão, responsável por $56 \%$ da produção da região. Quando comparado ao cenário nacional, Goiás ainda precisa melhorar a produtividade para que possa ganhar mais destaque; nessa comparação, Goiás é responsável por apenas $10 \%$ da produção. 
Tabela 2 - Produção de feijão (toneladas) de Goiás, do Centro-Oeste e do Brasil e participação da produção goiana na produção do Centro-Oeste e do Brasil, 1990, 1995, 2000, 2005, 2010 e 2013

\begin{tabular}{|c|c|c|c|c|c|c|c|c|c|c|c|c|}
\hline \multirow[t]{2}{*}{ Local } & \multicolumn{2}{|c|}{1990} & \multicolumn{2}{|c|}{1995} & \multicolumn{2}{|c|}{2000} & \multicolumn{2}{|c|}{2005} & \multicolumn{2}{|c|}{2010} & \multicolumn{2}{|c|}{2013} \\
\hline & $\mathrm{t}$ & $\%$ & $\mathrm{t}$ & $\%$ & $\mathrm{t}$ & $\%$ & $\mathrm{t}$ & $\%$ & $\mathrm{t}$ & $\%$ & $\mathrm{t}$ & $\%$ \\
\hline Brasil & 2.234 .467 & 100 & 2.946 .168 & 100 & 3.056 .289 & 100 & 3.021 .641 & 100 & 3.158 .905 & 100 & 2.892 .599 & 100 \\
\hline Centro-Oeste & 191.322 & 9 & 188.498 & 6 & 267.136 & 9 & 406.978 & 13 & 503.573 & 16 & 626.239 & 22 \\
\hline Goiás & 118.960 & 5 & 132.350 & 4 & 200.415 & 7 & 280.461 & 9 & 288.816 & 9 & 294.027 & 10 \\
\hline
\end{tabular}

Fonte: elaborada pelos autores a partir de dados de IBGE (2014).

A Tabela 3 mostra a distribuição do número de municípios necessários para alcançar 25\%, 50\%, 75\% e 100\% da produção goiana de feijão nos anos 1990, 1995, 2000, 2005, 2010 e 2013.

Fica visível que com o passar dos anos houve uma diminuição no número de municípios que participavam da produção goiana de feijão. Em 1990, Goiás contava com 184 municípios produtores responsáveis por uma produção anual de 118.960 toneladas. No início dos anos 2000 o número de municípios no estado caiu de 184 para 155 (-16\%), mas o efeito dessa diminuição não foi sentido na produção total de feijão, que saltou de 118.960 toneladas para 200.415 (+68\%). O efeito se seguiu com o passar dos anos. Em 2010 o número de municípios produtores de feijão caiu para 108, diminuição de $31 \%$ em relação a 2000 . No entanto, a produção teve um aumento de quase $41 \%$ em relação aos anos 2000, saltando de 200.415 toneladas para 288.816 toneladas de feijão. Houve um processo de consolidação da produção em um número menor de municípios, com sistemas de produção mais tecnificados, resultando em produtividades mais elevadas.

Tabela 3 - Distribuição dos municípios produtores de feijão no estado de Goiás, de 1990 a 2013, em anos selecionados, ordenados por quantidade produzida

\begin{tabular}{|c|c|c|c|c|c|c|}
\hline \multirow[t]{2}{*}{ Produto } & \multirow[t]{2}{*}{ Ano } & \multicolumn{5}{|c|}{ Número de municípios } \\
\hline & & Q1 & Q2 & Q3 & Q4 & Total \\
\hline & 1990 & 147 & 21 & 11 & 5 & 184 \\
\hline \multirow{3}{*}{ Feijão } & 1995 & 143 & 21 & 8 & 4 & 176 \\
\hline & 2000 & 143 & 9 & 2 & 1 & 155 \\
\hline & 2005 & 121 & 6 & 2 & 1 & 130 \\
\hline
\end{tabular}




\begin{tabular}{cccccc}
2010 & 96 & 8 & 2 & 2 & 108 \\
2013 & 80 & 8 & 3 & 2 & 93 \\
\hline Variação 2013/1990 (\%) & $-46 \%$ & $-62 \%$ & $-73 \%$ & $-60 \%$ & $-49 \%$ \\
\hline
\end{tabular}

Fonte: elaborada pelos autores a partir de dados de IBGE (2014).

Em relação a 1990 houve uma clara concentração da produção de feijão em um número reduzido de municípios responsáveis por pelo menos $25 \%(\mathrm{Q} 4)$ e $50 \%(\mathrm{Q} 3)$ da produção do estado. Um fator que pode ser responsável por essa concentração é a expansão da cultura da soja, que teve um salto nos anos 1990, seguida do acompanhamento dos bons preços no mercado nacional e internacional que levou à substituição de lavouras pela cultura da soja (CONAB, 2014a).

A concentração ocorrida depois dos anos 2000 pode ser reflexo da valorização dos preços dos derivados da cana-de-açúcar, que alcançaram notoriedade no cenário nacional, ganhando incentivos e apoio por parte do governo. Além disso, a expansão da cultura encontrou facilidades no estado de Goiás por apresentar bons preços e rentabilidade alta para os produtores, assim a cultura da cana ganhou espaços e substituiu culturas que antes eram consolidadas e apresentavam certa instabilidade no mercado, fazendo com que os produtores procurassem investir nessas culturas que apresentam um mercado mais estável.

Essa concentração pode ser resultado da utilização de técnicas mais avançadas que possibilitaram a fragmentação da produção de feijão no estado de Goiás (MACHADO et al., 2009). A safra atualmente é feita em três períodos, denominados primeira, segunda e terceira safras. Essa fragmentação é possível graças à utilização da irrigação, principalmente via pivô central, o que possibilita maior exploração dos preços e a programação da produção para quando o mercado apresentar menores quantidades disponíveis. Em reflexo, tem-se melhores preços para os produtores (EMBRAPA, 2014).

O Quadro 1 mostra os nomes dos municípios que eram responsáveis por pelo menos $25 \%$ da produção (Q4). Percebe-se que houve uma tendência de mudanças dos municípios produtores de feijão no decorrer dos anos, mudando de municípios e concentrando em apenas um município no ano 2000. Assim, ficou o município de Cristalina responsável por mais de $25 \%$ da produção de feijão goiano, com um 
percentual de produção de 32,27\% da produção goiana de feijão, totalizando 64.680 toneladas de feijão anuais.

Quadro 1 - Municípios responsáveis por pelo menos $25 \%$ da produção de feijão de

Goiás, em anos selecionados

\begin{tabular}{|c|c|c|c|c|c|c|}
\hline \multirow[t]{2}{*}{ Produto } & \multicolumn{6}{|c|}{ Municípios responsáveis por pelo menos $25 \%$ da produção em ordem decrescente de importância } \\
\hline & 1990 & 1995 & 2000 & 2005 & 2010 & 2013 \\
\hline Feijão & $\begin{array}{l}\text { Itapuranga } \\
\text { Itaberaí } \\
\text { Jaraguá } \\
\text { Petrolina de Goiás } \\
\text { Catalão }\end{array}$ & $\begin{array}{l}\text { Itaberaí } \\
\text { Luziânia } \\
\text { Cristalina } \\
\text { Campo Alegre de Goiás }\end{array}$ & Cristalina & Cristalina & $\begin{array}{l}\text { Cristalina } \\
\text { Luziânia }\end{array}$ & $\begin{array}{l}\text { Cristalina } \\
\text { Luziânia }\end{array}$ \\
\hline
\end{tabular}

Fonte: elaborado pelos autores a partir de dados de IBGE (2014).

Em 2013 Cristalina se manteve entre os municípios que produziam pelo menos $25 \%$ da produção goiana de feijão, dividindo o posto com o município de Luziânia. Cristalina ainda era responsável por 19,39\% da produção goiana de feijão, com volume de 57 mil toneladas de feijão anuais. Somando os dois municípios, eles foram responsáveis por 32,04\% da produção goiana de feijão, com um volume de 94.200 toneladas de feijão, demonstrando que Goiás passou por um processo de concentração da sua produção.

\subsection{Concentração da produção em Mato Grosso do Sul}

A produção de feijão no Mato Grosso do Sul é caracterizada por sua concentração e pela pouca distribuição de zonas produtoras. Em 2013, a microrregião de Dourados foi responsável pela maior parte da produção de feijão do estado, respondendo por $66 \%$ da produção estadual, o que demonstra que houve uma concentração da produção no ano de 2010 em uma única microrregião. A região de Iguatemi, que ficou em segundo lugar na produção de feijão em 2010, foi responsável por $11 \%$ da produção, demonstrando ainda mais a importância da microrregião de Dourados na produção total de feijão do estado de Mato Grosso do Sul. A Tabela 4 demonstra o ranking da produção das microrregiões e sua respectiva produção. 
Tabela 4 - Produção de feijão (toneladas) por microrregiões em Mato Grosso do Sul, 2010.

\begin{tabular}{lc}
\hline Microrregião & Produção (t) \\
\hline Dourados & 15.986 \\
Bodoquena & 3.019 \\
Cassilândia & 2.074 \\
Iguatemi & 3.500 \\
Nova Andradina & 1.912 \\
Iguatemi & 1.671 \\
Três Lagoas & 669 \\
Aquidauana & 625 \\
Campo Grande & 540 \\
Alto Taquari & 391 \\
Baixo Pantanal & 360 \\
Paranaíba & 316 \\
\hline Total & 27.563 \\
\hline
\end{tabular}

Fonte: elaborada pelos autores a partir de dados de IBGE (2014).

A Tabela 5 demonstra a participação de Mato Grosso do Sul na produção de feijão do Centro-Oeste e do Brasil nos anos 1990, 1995, 2000, 2005, 2010 e 2013. O que fica evidente é que o estado de Mato Grosso do Sul apresenta pouca influência na produção de feijão na região Centro-Oeste, com oscilações na produção nos anos estudados. No cenário nacional da produção de feijão, o Mato Grosso do Sul é inexpressivo, participando com apenas $1 \%$ da produção nacional.

Tabela 5 - Produção de feijão (toneladas) de Mato Grosso do Sul, do Centro-Oeste e do Brasil e participação da produção sul-mato-grossense na produção do Centro-Oeste e do Brasil, 1990, 1995, 2000, 2005, 2010 e 2013

\begin{tabular}{|c|c|c|c|c|c|c|c|c|c|c|c|c|}
\hline \multirow[t]{2}{*}{ Local } & \multicolumn{2}{|c|}{1990} & \multicolumn{2}{|l|}{1995} & \multicolumn{2}{|c|}{2000} & \multicolumn{2}{|c|}{2005} & \multicolumn{2}{|c|}{2010} & \multicolumn{2}{|l|}{2013} \\
\hline & $\mathrm{t}$ & $\%$ & $\mathrm{t}$ & $\%$ & $\mathrm{t}$ & $\%$ & $\mathrm{t}$ & $\%$ & $\mathrm{t}$ & $\%$ & $\mathrm{t}$ & $\%$ \\
\hline Brasil & 2.234 .467 & 100 & 2.946 .168 & 100 & 3.056 .289 & 100 & 3.021 .641 & 100 & 3.158 .905 & 100 & 2.892 .599 & 100 \\
\hline Centro-Oeste & 191.322 & 9 & 188.498 & 6 & 267.136 & 9 & 406.978 & 13 & 503.573 & 16 & 626.239 & 22 \\
\hline Mato Grosso do Sul & 33.966 & 2 & 23.590 & 1 & 10.019 & 0 & 23.595 & 1 & 31.937 & 1 & 27.563 & 1 \\
\hline
\end{tabular}

Fonte: elaborada pelos autores a partir de dados de IBGE (2014). 
A Tabela 6 mostra a distribuição do número de municípios necessários para alcançar $25 \%, 50 \%, 75 \%$ e $100 \%$ da produção sul-mato-grossense de feijão nos anos 1990, 1995, 2000, 2005, 2010 e 2013.

O caso observado na produção de feijão no Mato Grosso do Sul é diferente do apresentado em Goiás, pois a produção, apesar de concentrada, não teve um aumento da concentração nos municípios que são os maiores produtores (Q4). Houve estabilidade dos municípios produtores, como foi observado no estado de Goiás. Houve uma tendência para a concentração no terceiro quartel (Q3), em que cinco municípios eram responsáveis por representar o terceiro quartel em 1990, mas caiu para três municípios, mantendo-se assim até 2013. O mesmo efeito, porém mais visível, pode ser observado no segundo quartel $(\mathrm{Q} 2)$. No estado inteiro, houve tendência para a concentração da produção; nos anos 1990, 69 municípios eram responsáveis pela totalidade da produção de feijão sul-mato-grossense, caindo para 49 em 2013, uma queda de $29 \%$ no número de municípios produtores de feijão.

A concentração observada nos municípios sul-mato-grossenses não foi muito expressiva, e aconteceu em porcentagens pequenas, o que não impediu que diminuíssem os municípios responsáveis pela produção de feijão no estado.

Tabela 6 - Distribuição dos municípios produtores de feijão no estado de Mato Grosso do Sul, de 1990 a 2013, em anos selecionados, ordenados por quantidade produzida

\begin{tabular}{lllllll}
\hline Produto & Ano & \multicolumn{5}{c}{ Número de municípios } \\
\cline { 3 - 7 } & & Q1 & Q2 & Q3 & Q4 & Total \\
\hline \multirow{4}{*}{ Feijão } & 51 & 11 & 5 & 2 & 69 \\
& 1990 & 50 & 11 & 5 & 2 & 68 \\
& 2000 & 46 & 10 & 2 & 3 & 61 \\
& 2005 & 43 & 9 & 5 & 3 & 60 \\
& 2010 & 48 & 5 & 2 & 2 & 57 \\
\hline Variação 2013/1990 (\%) & $-25 \%$ & $-45 \%$ & $-40 \%$ & $0 \%$ & $-29 \%$ \\
\hline
\end{tabular}

Fonte: elaborada pelos autores a partir de dados de IBGE (2014).

Houve uma pequena tendência para a concentração da produção sul-matogrossense de feijão em municípios que apresentaram maiores investimentos em 
tecnologias e novas formas de cultivo, pois alguns municípios apresentaram a troca da cultura por cultivos mais rentáveis e que apresentam maiores investimento por parte do governo (CONAB, 2014b). Outro fator que pode ter influenciado na pequena tendência de concentração em relação ao número total de municípios produtores de feijão foi a expansão da produção da bovinocultura de corte em sistema expansivo, em que o gado ocupa as áreas que eram utilizadas para cultivo de culturas anuais (BEEFPOINT, 2012).

O que chama a atenção é a oscilação na quantidade produzida de feijão pelos municípios sul-mato-grossenses, que nos anos 1990 produziram 33.966 toneladas de feijão. Nos anos 2000, esse número caiu para 10.019 toneladas, uma diminuição de $70 \%$ da produção do estado. Já nos anos 2010, houve uma recuperação da produção de feijão no estado, que passou de 10.019 em 2000, para 31.937 em 2010, um aumento de $219 \%$ da produção estadual, demonstrando que o estado teve uma recuperação da produção.

O Quadro 2 mostra os nomes dos municípios que eram responsáveis por pelo menos $25 \%$ da produção estadual. Percebe-se que houve uma tendência de mudanças dos principais municípios produtores de feijão no decorrer dos anos. Em 1990 os municípios de Dourados e Angélica eram responsáveis por $25,51 \%$ da produção de feijão do estado.

Quadro 2-Municípios responsáveis por pelo menos 25\% da produção de feijão de Mato Grosso do Sul, em anos selecionados

\begin{tabular}{|c|c|c|c|c|c|c|}
\hline \multirow[t]{2}{*}{ Produto } & \multicolumn{6}{|c|}{ Municípios responsáveis por pelo menos $25 \%$ da producão em ordem decrescente de } \\
\hline & 1990 & 1995 & 2000 & 2005 & 2010 & 2013 \\
\hline Feijão & $\begin{array}{l}\text { Dourados } \\
\text { Angélica }\end{array}$ & $\begin{array}{l}\text { Dourados } \\
\text { São Gabriel do } \\
\text { Oeste }\end{array}$ & $\begin{array}{l}\text { Caarapó } \\
\text { Ponta Porã } \\
\text { Chapadão do } \\
\text { Sul }\end{array}$ & $\begin{array}{l}\text { Caarapó } \\
\text { Ponta Porã } \\
\text { Sidrolândia }\end{array}$ & $\begin{array}{l}\text { Ponta Porã } \\
\text { Caarapó }\end{array}$ & $\begin{array}{l}\text { Ponta Porã } \\
\text { Caarapó }\end{array}$ \\
\hline
\end{tabular}

Fonte: elaborado pelos autores a partir de dados de IBGE (2014).

Após 2000, outros municípios como Caarapó, Ponta Porã e Chapadão do Sul ocuparam a posição de principais produtores estaduais. Mais recentemente (2010-2013), apenas Ponta Porã e Caarapó permanecem como os principais municípios produtores (Q4) de feijão no Mato Grosso do Sul. 


\subsection{Concentração da produção em Mato Grosso}

A produção de feijão em Mato Grosso se assemelha com a produção de Goiás, já que é realizada em três etapas, primeira, segunda e terceira safras, nas quais são exploradas as áreas irrigadas com pivô central. A Tabela 7 apresenta as principais microrregiões produtoras de feijão no estado de Mato Grosso em 2013. O que pode ser observado é que a microrregião de Alto Teles Pires é a principal microrregião produtora, responsável por $44 \%$ da produção total do estado. Primavera do Leste e Parecis ocupam respectivamente o segundo e o terceiro lugar na produção; Primavera do Leste é responsável por 18\% da produção e Parecis, por 11\% da produção estadual.

Tabela 7 - Produção de feijão (toneladas) por microrregiões do estado de Mato Grosso,

2013

\begin{tabular}{lc}
\hline Microrregião & Produção \\
\hline Alto Teles Pires & 124.812 \\
Primavera do Leste & 50.715 \\
Parecis & 30.410 \\
Sinop & 21.012 \\
Canarana & 16.736 \\
Tesouro & 12.576 \\
Arinos & 6.127 \\
Rondonópolis & 3.591 \\
Alto Araguaia & 3.286 \\
Tangará da Serra & 3.284 \\
Aripuanã & 2.822 \\
Norte Araguaia & 2.180 \\
Paranatinga & 560 \\
Rosário Oeste & 405 \\
Alto Guaporé & 353 \\
Jauru & 290 \\
Alto Pantanal & 198 \\
Alta Floresta & 116 \\
& \\
\hline
\end{tabular}




\begin{tabular}{lc} 
Colíder & 105 \\
Cuiabá & 23 \\
Alto Paraguai & 16 \\
\hline Total & 279.617
\end{tabular}

Fonte: elaborada pelos autores a partir de dados de IBGE (2014).

$\mathrm{Na}$ Tabela 8 é possível visualizar a produção mato-grossense em relação à produção do Centro-Oeste e à produção nacional de feijão. O estado de Mato Grosso ganhou importância na produção de feijão no Centro-Oeste, como fica claro na Tabela 8, aumentando sua produção, que no ano de 1990 era de 30.890 toneladas de feijão, mas com uma pequena queda na produção nos anos 2000, indo para 24.663 toneladas, e seguindo para alcançar a produção de 133.802 toneladas. Esse efeito se deve ao fato de o feijão ter alcançado melhores preços no mercado e pelo recuo de algumas atividades agrícolas do Mato Grosso (CONAB, 2014b).

No cenário do Centro-Oeste, em 2013, o Mato Grosso foi responsável pela produção de $45 \%$ do feijão. Quando comparamos ao cenário nacional, Mato Grosso, como já foi ressaltado, ganhou importância em relação à produção de feijão, o que se deve ao incremento na adubação e aos novos manejos no plantio, que auxiliaram no aumento da produção (CONAB, 2014b). No cenário nacional, em 2013, o Mato Grosso foi responsável por $10 \%$ da produção, e, se os incentivos continuarem e os trabalhos sejam no sentindo de melhorar cada vez mais a produtividade, o estado poderá aumentar ainda mais sua produção de feijão.

Tabela 8 - Produção de feijão (toneladas) de Mato Grosso, do Centro-Oeste e do Brasil e participação da produção mato-grossense na produção do Centro-Oeste e do Brasil, 1990, 1995, 2000, 2005, 2010 e 2013

\begin{tabular}{|c|c|c|c|c|c|c|c|c|c|c|c|c|}
\hline \multirow[t]{2}{*}{ Local } & \multicolumn{2}{|c|}{1990} & \multicolumn{2}{|c|}{1995} & \multicolumn{2}{|c|}{2000} & \multicolumn{2}{|l|}{2005} & \multicolumn{2}{|c|}{2010} & \multicolumn{2}{|c|}{2013} \\
\hline & $\mathrm{t}$ & $\%$ & $\mathrm{t}$ & $\%$ & $\mathrm{t}$ & $\%$ & $\mathrm{t}$ & $\%$ & $\mathrm{t}$ & $\%$ & $\mathrm{t}$ & $\%$ \\
\hline Brasil & 2.234 .467 & 100 & 2.946 .168 & 100 & 3.056 .289 & 100 & 3.021 .641 & 100 & 3.158 .905 & 100 & 2.892 .599 & 100 \\
\hline Centro-Oeste & 191.322 & 9 & 188.498 & 6 & 267.136 & 9 & 406.978 & 13 & 503.573 & 16 & 626.239 & 22 \\
\hline Mato Grosso & 30.890 & 1 & 23.220 & 1 & 24.663 & 1 & 66.122 & 2 & 133.813 & 4 & 279.617 & 10 \\
\hline
\end{tabular}

Fonte: elaborada pelos autores a partir de dados de IBGE (2014).

A Tabela 9 mostra a distribuição do número de municípios necessários para alcançar 25\%, 50\%, 75\% e 100\% da produção mato-grossense de feijão nos anos 1990 , 1995, 2000, 2005, 2010 e 2013. 
A produção de feijão no Mato Grosso não diferiu da produção de Goiás e Mato Grosso do Sul, pois poucos municípios são responsáveis pela maior parte da produção de feijão. Nos anos 1990, dois municípios eram responsáveis por $25 \%$ da produção de feijão do estado. Em 1995 esse número subiu para três, porém voltou a ser de apenas dois a partir de 2000, demonstrando que existe concentração de produção de feijão em alguns municípios especializados na produção desse grão.

Quando observado o terceiro quartel (Q3), houve uma oscilação nos municípios que o compunham. Em 1990, cinco municípios eram responsáveis pela formação desse quartel, em 1995 e 2000 oito municípios formavam esse quartel. A partir de 2005 o número de municípios nesse grupo diminuiu para três e, em 2010, apenas um município. Isso se deve ao aumento da produção dos municípios que formam o quarto quartel, fazendo com que menos municípios façam parte da formação do terceiro quartel.

Outro aspecto que pode ser observado foi que Mato Grosso seguiu uma tendência diferente da do estado de Goiás e Mato Grosso do Sul, que, no decorrer dos anos, apresentaram diminuição dos municípios que produziam feijão. No estado do Mato Grosso o número de municípios produtores aumentou, indo de 73 municípios em 1990, para 93 municípios produtores em 2013, ou seja, um aumento de $27 \%$ no número de municípios produtores.

Tabela 9 - Distribuição dos municípios produtores de feijão no estado de Mato Grosso, de 1990 a 2013, em anos selecionados, ordenados por quantidade produzida

\begin{tabular}{lllllll}
\hline Produto & Ano & \multicolumn{5}{c}{ Número de municípios } \\
\cline { 3 - 7 } & & Q1 & Q2 & Q3 & Q4 & Total \\
\hline \multirow{4}{*}{ Feijão } & 59 & 7 & 5 & 2 & 73 \\
& 1990 & 49 & 14 & 8 & 4 & 75 \\
& 2000 & 60 & 15 & 8 & 2 & 85 \\
& 2005 & 78 & 8 & 3 & 2 & 91 \\
& 2010 & 75 & 4 & 1 & 2 & 82 \\
\hline Variação 2013/1990 (\%) & 32 & 8 & 1 & 2 & 93 \\
\hline
\end{tabular}

Fonte: elaborada pelos autores a partir de dados de IBGE (2014). 
Foi estável a concentração da produção apresentada pelo estado de Mato Grosso, pois o número total de municípios produtores e o número de municípios em Q4 não diminuíram em relação a 1990. O que fica claro é que houve um aumento significativo na produção do estado, que foi de 30.890 toneladas em 1990 para 279.617 toneladas em 2013, um aumento de $805 \%$ na produção de feijão, fazendo com que o estado aumentasse sua participação relativa na produção de feijão no cenário nacional, como já comentado.

No Quadro 3 é possível visualizar os nomes dos municípios maiores produtores e que, juntos, eram responsáveis por pelo menos $25 \%$ da produção de feijão do estado (Q4). Houve uma mudança nos municípios produtores de feijão no estado, já que, em 1990, Campo Novo do Parecis e Tangará da Serra formavam o quarto quartel e eram responsáveis pela produção de $25,16 \%$ de todo o feijão mato-grossense.

Quadro 3 - Municípios responsáveis por pelo menos 25\% da produção de feijão de

Mato Grosso, em ordem decrescente de importância

\begin{tabular}{|c|c|c|c|c|c|c|}
\hline \multirow[t]{2}{*}{ Produto } & \multicolumn{6}{|c|}{ Municípios responsáveis por pelo menos $25 \%$ da produção em ordem decrescente de importância } \\
\hline & 1990 & 1995 & 2000 & 2005 & 2010 & 2013 \\
\hline Feijão & $\begin{array}{l}\text { Campo Novo do } \\
\text { Parecis } \\
\text { Tangará da } \\
\text { Serra }\end{array}$ & $\begin{array}{l}\text { Lucas do Rio } \\
\text { Verde } \\
\text { Tangará da } \\
\text { Serra } \\
\text { Cáceres } \\
\text { Alta Floresta }\end{array}$ & $\begin{array}{l}\text { Sorriso } \\
\text { Primavera do } \\
\text { Leste }\end{array}$ & $\begin{array}{l}\text { Sorriso } \\
\text { Primavera do } \\
\text { Leste }\end{array}$ & $\begin{array}{l}\text { Primavera do } \\
\text { Leste } \\
\text { Sorriso }\end{array}$ & $\begin{array}{l}\text { Sorriso } \\
\text { Primavera do } \\
\text { Leste }\end{array}$ \\
\hline
\end{tabular}

Fonte: elaborado pelos autores a partir de dados de IBGE (2014).

Em 2000, houve mudanças de municípios produtores de feijão, sendo que o quarto quartel foi formado pelos municípios de Sorriso e Primavera do Leste, que foram responsáveis pela produção de 26,57\% do feijão mato-grossense naquele ano. Em 2010, houve apenas a inversão dos municípios de Primavera do Leste e Sorriso, mas ambos ficaram no quarto quartel, responsáveis por 42,83\% da produção de feijão no estado. Em 2013, esses dois municípios continuaram responsáveis por 39,54\% da produção do estado, e Sorriso voltou a ser o maior produtor. Fica evidente, portanto, que há uma grande concentração da produção em apenas dois polos produtivos: Sorriso e Primavera 
do Leste. Em 2013, o município de Sorriso, sozinho, foi responsável por 23,37\% da produção de feijão do estado.

\section{Considerações finais}

O município de Cristalina se destaca como o polo produtor de feijão no estado de Goiás em relação aos outros municípios produtores, e em 2005 foi responsável por quase $35 \%$ da produção total de feijão do estado de Goiás. Esse fato caracteriza-se como uma concentração da produção em apenas uma região, e em 2013 mesmo que Cristalina tenha dividido o topo da produção com Luziânia, ainda foi responsável por mais de $19 \%$ da produção goiana de feijão, deixando claro que nos últimos anos houve uma grande tendência enorme para a concentração da produção de feijão no estado de Goiás.

O estado de Mato Grosso do Sul não apresenta importância na produção de feijão regional nem na produção nacional e não contribuiu com quantidades relevantes de feijão para o mercado. O município de Ponta Porã destaca-se em relação aos outros municípios produtores de feijão. O Estado também apresenta concentração na sua produção de feijão, e o maior montante da produção está sob o encargo de apenas alguns poucos municípios.

O cenário do estado de Mato Grosso não é diferente em relação ao estado de Goiás e do Mato Grosso do Sul, com duas diferenças: o estado apresentou um aumento no número de municípios produtores de feijão ao longo do período estudado, o que não se observou nos outros dois estados e apresentou um aumento vertiginoso na sua produção de feijão. Os municípios de Sorriso e Primavera do Leste foram os que mais apresentaram importância no cenário de produção de feijão no estado. A, assim como os outros dois estados, Mato Grosso também apresentou concentração na produção de feijão.

\section{REFERÊNCIAS}

BEEFPOINT. Associação dos produtores de carne. Cadeia produtiva da bovinocultura. Disponível em: <http://www.beefpoint.com.br>. Acessado em: 22 jan. 2012. 
CONAB. Companhia Nacional de Abastecimento. Mercado de Soja: evolução. Disponível em: <http://www.conab.gov.br>. Acesso em 13 dez. 2014a.

CONAB. Companhia Nacional de Abastecimento. Mercado de Feijão: evolução. Disponível em: <http://www.conab.gov.br>. Acesso em 13 dez. 2014b.

EMBRAPA. Empresa Brasileira de Pesquisa Agropecuária. Irrigação do feijoeirocomum. Disponível em: <http://www.cnpaf.embrapa.br>. Acesso em: 13 dez. 2014.

FERREIRA, C. M.; DEL PELOSO, M. J.; FARIA, L. C. Feijão na economia nacional. Santo Antônio de Goiás: Embrapa Arroz e Feijão, 2002. 47p. (Embrapa Arroz e Feijão. Documentos, 135).

IBGE. Instituto Brasileiro de Geografia e Estatística. Série: Produção Agrícola Municipal. Pesquisa Agrícola Municipal - PAM. Diversos anos. Disponível em: <http://www.sidra.ibge.gov.br>. Acesso em: 7 dez. 2014.

MACHADO, P. L. O. A.; FERREIRA, C. M.; DEL PELOSO, M. J.; NASCENTE, A. S.; BRESEGHELlO, F.; AIDAR, H.; KLUTHCOUSKI, J.; STONE, L. F.; MORAIS, O. P.; RABELO, R. R.; COBUCCI, T. Estratégia de comunicação e negócio e transferência de tecnologia na Embrapa Arroz e Feijão. Santo Antônio de Goiás: Embrapa Arroz e Feijão, 2009. 24p. (Embrapa Arroz e Feijão. Documentos, 252).

WANDER, A. E.; GAZZOLA, R.; GAZZOLA, J.; RICARDO, T. R.; GARAGORRY, F. L. Evolução da produção e do mercado mundial do feijão. XLV Congresso da Sociedade Brasileira de Economia, Administração e Sociologia Rural. 2007. Disponível em: <http://www.sober.org.br/palestra/6/369.pdf>. Acesso em: 8 dez. 2014.

WANDER, A. E. Padrões de concentração das cinco principais atividades do agronegócio do Centro-Oeste. In: CALADO, L. R.; COSTA FILHO, B. A.; CARVALHO FILHO, N.; OLIVEIRA, R. D. Temas em administração. Espírito Santo: Opção Editora. 2011. p. 26-36.

Recebimento dos originais: 02/08/2015

Aceitação para publicação: 27/08/2015 